\title{
O ESPAÇO NA CRITTICA DA RAZÃO PURA
}

\section{I - O ESPAÇO NA ESTETICA TRANSCENDENTAL}

No exame do problema do espaço em Kant que iremos proceder, contentar-nos-emos em tornar como referência a Crítica da Razão Pura.

Há, certamente en re os escritos "pré-críticos", os que tematizam expressamente o prob!ema do espaço, ao menos sob um de seus aspectos, como é o caso de Von dem ersten Grunde des Unterschiedesder gegenden im Raume, datado, de 1768. Mas além de não corresponder ao pensamento kantiano da maturidade seu exame, assim como o do tema do espaço naquilo que poderiamos chamar a totalidade da obra de Kant exigiriam provavelmente, que a pesquisa fosse limitada a Kant, e se enquadrasse num projeto diferente do nosso. Ora, o que pretendemos é sobretudo destacar uma problemática do espaço através das questões que a leitura desses três filósofos nos sugere (1), em algumas de suas obras mais representativas no que concerne à nossa interrogação.

Mas, mesmo que a proposta de considerar somente a Crítica da Razão Pura fosse ditada pela economia interna de nosso projeto, a escolha desta obra se justificaria, no interior da obra de Kant, pois é aí que a determinação do estatuto do espaço se faz de maneira temática e em relação ao conjunto da problemática kantiana, determinação que não será retificada na continuidade da obra.

Quanto à presente leitura da Crí ica da Razão Pura, ela foi orientada por outras leituras, das quais citaremos aqui apenas duas que reputamos decisivas: a de Heidegger, em "Kant et le Prob'éme de la Métaphysique" e a de G. Granger, em "Pensée Formelle et Sciences de l'Homme".

(1) Este trabalho faz parte de um tríptico em que tentamos questionar o estatuto do espaço nas filosofias de Kant, Bergson e até o Ser $e$ o Tempo de Heidegger. No que se refere a Kant, trata-se aqui de acentuar a solidariedade sistemática entre a posição central da Subjetividade Transcendental, o primado do tempo sobre o espaço e a ausência de tematização da linguagem. Uma tal solidariedade impediria que a questão do espaço se pudesse pôr no horizonte do pensamento do habitar. 
Dois horizontes diferentes de pensamen o atrairam nossa atenção para aspectos da obra de Kant, os quais, a uma consideração mais profunda, se revelariam como que ligados. De um lado, Heidegger segue a via de uma afirmação do primado do tempo na obra de Kant. De outro lado, Granger faz notar certas limitações internas da epistemologia kantiana, como a não tema ização da linguagem e o caráter não laborioso da atividade de conhecimento.

Antes de tentar compreender sobre quê se fundam estas indicações, acrescentemos alguns reparos acerca dessas duas leituras, em relação às quais reconhecemos a incidência sobre nossa maneira de considerar a concepção kantiana de espaço.

Digamos primeiramente que a obra de G. Granger não sendo sobre Kant, nos fornece apenas considerações sumárias sobre a importância epistemológia da Crítica da Razão Pura. Mas tais considerações possuem, a nossos olhos o mérito de indicar as lacunas da teoria do conhecimento veiculada na Crítica - lacunas que não somente restringem o alcance epistemo'ógico do projeto kantiano, como também são responsáveis pela maneira como se organizam os elementos do conhecimento que foram tomados em connsideração, embora este projeto seja considerado aqui apenas sob o ângulo do problema epistemológico ao qual não se reduz.

Ora, totalmente diferente é a perspectiva de "Kant et le Probléme de la Métaphysique". Não se pode ignorar o fato de que Heiddegger tenta aí, uma interpretação global da primeira Crítica. Nós a assumimos? Se não, por que reter a indicação do primado do tempo?

A tese heideggeriana sustenta, que a Crítica põe, em última análise, a questão da instauração do fundamento da metafísica, e que esta questão encontra-se essencialmente ligada ao desvelamento ontológico da finitude no homem. Nesta instauração, o ente que se dá como fenômeno na experiência, se revela pressupondo o horizonte de uma pré-compreensão do ser, a qual comporta uma relação intrínseca com a finitude.

Mas uma tal ligação entre a instauração do fundamento da meafísica e o problema da finitude no homem tem como contrapartida na interpretação heideggeriana, de um lado o esquecimento de que a razão, segundo Kant, apesar de seu caráter finito, pode auto-criticar-se, isto é, delimitar e articular a esfera de seu poder, portanto sobrevoar a si mesma, e não simplesmente experimentar-se no seio de sua finitude; de outro lado, a recusa de estabelecer a importância da função não exclusivamente negativa do supra-sensível no pensa- 
mento de Kant (2). Em outras palavras, a interpretação heideggeriana se contenta com afastar o supra-sensível, como fruto de uma ilusão transcendental, em proveito de uma problemática do ser em geral.

Ora, se a Crítica revela a pretensão absurda do entendimen o de conhecer os "objetos" super-sensíveis, ela não renuncia entretanto a preparar o terreno para que eles possam ser considerados fora da esfera do conhecer, como também a sustentar que nesta consideração está o interêsse mais fundamen'al da razão.

A interpretação heideggeriana tenderia, com efeito, a amenizar a importância do limite traçado pelo desprezo de sua dup'a função: de um lado, e manifestação do que pertence à esfera do poder de conhecer e da maneira como ele se articula; de outro, a determinação do que ultrapassa este poder e que pode constituir objeto não de ciência mas de fé. Embora Kant deseje assim, relacionar a razão, se bem que apenas no seu uso prático, ao domínio do não-conhecível, que a faz medir seu poder de conhecer, a interpretação recusa conservar o interesse do que está para além da esfera limitada, para investigar somente as implicações daquilo que sobressai de positivo no interior desta.

Temos, pois, o direito de recusar o alcance geral desta interpretação. Permanece, entretanto, o fato de que a Crítica autoriza uma leitura como a de Heidegger, na medida que, articulando a esfera de nosso poder de conhecer, ela produz uma certa configuração da finitude do homem. Permite, assim, destacar as implicações relativas ao ser do homem em sua relação com o ser do ente, relação essencial ao ser do homem, e que seu poder de conhecer pressupõe .

Outrossim, esta !eitura da Crítica como instauração do fundamento da metafísica, na perspectiva de uma metafísica do Dasein que de alguma forma a prolonga, esclarecerá melhor o primado do tempo. Tal é a sugestão fundamental que aceitamos de "Kant et le Problème de la Métaphysique".

Efetuados esses reparos, que visavam salvaguardar o sentido do uso que fazemos da obra de Heidegger, poderemos interrogar agora a Crítica acerca do estatuto que nela recebe o espaço.

Por necessidade de exposição nossas questões serão reagrupadas em torno de três temas, que concernem tanto ao tempo quanto ao espaço.

(2) Cf. o recente e decisivo trabaiho de Gérard Lebrun "Kant et la fin de la Métaphysique, essai sur la "Critique de la Faculté de juger" Ed. Armand Colin, 1970 
1) - O espaço na Estética e o abso'uto do espaço euclidiano.

2) - As Antinomias matemáticas e o esquecimento do tempo.

3) - A Analítica dos Princípios e o primado do tempo, raiz rranscendental do espaço.

Percorrendo os feixes de questões reagrupadas em torno destes temas, pensamos poder estabelecer a solidariedade sistemática entre o estatuto do espaço em relação ao tempo, a ausência de tematização da linguagem e a impossibilidade de uma problemática da intersubjetividade na Crítica da Razão Pura.

\section{O espaço na Estética e o absıluto do espaço euclidiano.}

A Matemática, e em particular aqui, a Geometria, é um fato irrecusáve!, que desmente as teses empiristas sobre o espaço. Este parece ser o pon .o de partida da Estética Transcendental. Mas se a noção de espaço não é abstraída da experiência sensível, donde vem, se - e agora levando em conta a abordagem empirista o espaço não é nem uma coisa em si nem uma relação entre as coisas que nos seriam dadas de maneira diferente da intuição sensível?

Entre a impossibilidade de conceber a noção de espaço como constituída a partir da experiência sensível, caso em que a Geometria seria penetrada pela contingência - e é evidente que suas verdades possuem um caráter necessário - , e a impossibilidade de fazer do espaço uma coisa ou uma relação em si independente da sensibilidade, restará a Kant apenas a possibilidade de abrir esta via: o espaço é forma pura da intuição sensível.

Duas considerações parecem, primeiramente, sustentar a relação do espaço à sensibilidade mais do que ao entendimento, no que se refere à dualidade kantiana das faculdades .

10) O espaço é uma coordenada necessária válida para todos os fenômenos exteriores, isto é, para iudo o que, fora de nós, é susceptível de se tornar objeto de uma intuição empírica. Possui, pois, ligação com a intuição senșível.

2\%) As proposições geométricas que determinam sinte'icamente as propriedades do espaço devem depender da intuição sensível (a única que nos é possível), pois não há conhecimento sintético que dependa unicamente de conceitos. Da mesma forma, o espaço cujas propriedades são assim determinadas deve depender da intuição sensível.

Como encarar estas considerações? São elas independentes uma da ou ra no pensamento kantiano? 
Quanto à primeira, é sem dúvida irrefutável que todos os fenômenos empíricos são ordenados no espaço e consequentemente o pressupõem. O espaço pode assim ser tomado como forma da intuição sensível. Restaria perguntar se o espaço se reduz a isto.

Quanto à segunda, sem poder entrar nos detalhes da discussão, pode-se dizer que não é de maneira nenhuma incontestável que as proposições geométricas sejam sintéticas. Também dificilmente se pode sustentar, como faz Kant, que elas sejam essencialmente construidas na intuição sensível, já que a Geometria enquanto ciência matemática é dedutiva e portanto analítica.

O ba'anço dessas considerações não consistiria, entretanto, simplesmente na aceitação de uma e na recusa, ou, ao menos, na coniestação do alcance da outra. Pois elas não são dissociáveis, como se poderia crer.

Examinaremos agora aquilo que, já em Kant, estava implicado na tese do espaço como forma da intuição sensível.

\section{A - O espaço como forma da sensibilidade.}

Lembremos que a propósito da intuição sensível Kant chama forma o que unifica a diversidade do fenômeno segundo certas relações, por oposição a matéria do fenômeno, que corresponde ao que é dado pela sensação.

A Estética Transcendental terá, pois, que tema izar essas formas não empíricas que são o espaço e o tempo. Assim, é a propósito da sensibilidade, mas de uma sensibilidade pura, que se põe o problema do espaço.

Mas o que significa para Kant o espaço como forma da sensibilidade?

Vejamos por via de que enunciações nos é fornecido um meio de aproximação.

O espaço é primeiramente negado como conceito empírico que seria retirado da experiência dos fenômenos exteriores, pois ele é uma pressuposição de toda experiência externa. Enquan o tal ele é posto como uma "representação necessária a priori" que serve de fundamento a todas as intuições exteriores (3). Ele é, pois, aquilo sem o que não haveria intuição sensível dos fenômenos como estando

(3) Cf. Critique de la Raison Pure, trad. francesa de A. Tremesaygues e B. Pacaud, ed. de 1963; pg. 56. In ciamos o comentário da "Primeira Seç̧ão - Do espaço" da Estética Transcendental. 
fora de nós, justapostos entre si e colocados em lugares diferentes, e este fundamento reside em nós independente de toda experiência.

Há um argumento que sustenta esta tese, e que poderia derivar de algo como uma "variação imaginativa" no sentido husserliano: "Não podemos nunca representar-nos que não há espaço, embora possamos pensar que não há objetos no espaço". O espaço seria, pois, uma espécie de variante último da experiência, resistindo, relativamente a ela, a toda tentativa de negação, como o cogito cartesiano resistia à dúvida .

A segunda parte do argumento é menos clara. Se o espaço é forma dos fenômenos exteriores, como pode ser concebido independentemente destes fenômenos, a não ser por uma abstração metodológica, que a exposição metafísica, tal como Kant a entende, exclui? Mas ver-se-á na sequência da exposição, quando o próprio espaço é introduzido como uma intuição pura, que esta tese poderia valer como uma resposta à nossa objeção.

Além disto, a afirmação do espaço como uma "representação necessária a priori" se completa e de alguma maneira se explicita por esta outra, em que a noção de forma é novamente retomada: "o espaço não é nada mais do que a forma de todos os fenômenos dos sentidos externos, isto é, a condição subjetiva da sensibilidade sob a qua!, unicamente, nos é possível uma intuição exterior”.

Tentemos explicitar algumas das implicações contidas nestas afirmações...

O "aqui'o sem o que", ou dito de outra forma, a representação necessária a priori, não é nada mais do que uma condição subjetiva da sensibilidade. Como condição subjetiva da sensibilidade o espaço é assim, uma idealidade transcendental e a determinação dos fenômenos é unicamente devida à constituição do espírito humano.

Assim se realisa também, e precisamente a propósito do espaço, o primeiro passo desta "revolução copernicana" que Kant pretende realisar em Filosofia, o "núcleo central" do sistema sendo o sujeito transcendental de que o espaço torna-se uma das formas da receptividade.

Deixando provisoriamente de lado as características do modelo escolhido, salientemos entretanto que uma tal concepção do espaço implica em que a determinação espacial dos fenômenos possua um caráter de acabamento, para não dizer que ela não requer jamais um verdadeiro trabalho de objetivação.

Com efeito, Kant concebe a forma dos fenômenos exteriores, que é dada inteiramente no espírito, como contendo o princípio de 
suas relações. A partir daí, a aplicação das formas subjetivas aos fenômenos se faz por si mesma, o modo como isto se dá está inscrito nas propriedades formais do espírito. Do mesmo modo, a ciência não requer nenhum desvio através de uma construção e de uma inscrição objetivantes para que os fenômenos aí sejam especialmente determinados.

O que chamamos acabamento se traduz pois por uma visão estática da ciência, que tantas vezes já se salien ou em Kant, e a contrapartida do fato de que as condições puramente subjetivas sejam consideradas sem mais como o fundamento da objetividade.

Mas voltemos a Kant, e para compreender melhor que o espaço como forma dos fenômenos não é simplesmente a condição geral de sua represen ação, mas contém já o princípio de suas relações (dos fenômenos), independente de toda experiência, é preciso, segundo Kant, que a forma da intuição sensível seja considerada uma intuição pura, podendo ser tomada independentemente da relação aos fenômenos (4) .

Somos pois levados a considerar o outro aspecto do conceito kantiano de espaço, isto é, o espaço como intuição pura.

\section{B - O espaço como intuição pura .}

Notemos, de passagem, que é este aspecto do espaço que permite ligar mais estreitamente a exposição metafísica à exposição transcendental. Notemos também que, se se trata já, nesta última, da intuição pura do espaço como princípio da possibilidade dos conhecimentos, esta possibilidade se limitaria aos conhecimentos de tipo geométrico, não se referindo ainda ao conhecimento "strictu sensu", a saber, aquele que se refere aos objetos físicos, o qual pressupõe a dedução dos princípios da experiência .

\section{Consideremos agora em si mesmo este aspecto do espaço.}

$\mathrm{O}$ primeiro pensamento subjacente à tese do espaço como intuição pura é sua unidade prévia, na representação, em relação aos diferentes espaços particulares. Não podemos pois representar espaços particulares a não ser que tenhamos já a intuição a priori de um espaço único que os contém a todos.

(4) Cf. ibid. pg.. 58 - “... compreende-se fàcilmente como a forma de todos os fenômenos pode ser dada no espírito, anteriormente a toda percepção real - consequentemente a priori - e como, antes de toda experiência, ela pode, como intuição pura, na qual todos os objetos devem ser determinados, conter o princípio de suas relações". 
Esta é a razão pela qual o espaço não é um conceito geral sob o qual poderíamos subsumir os espaços particuares que seriam os únicos a serem dados, enquanto aquele seria apenas o que poderíamos pensar de geral nestes espaços particulares. Ao contrário, o espaço é dado como um, o que faz com que os espaços particulares possam aparecer apenas como limitações no seio do único e mesmo espaço, do qual temos a intuição pura.

Um tal pensamento certamente se integra ao conjunto da concepção kantiana de espaço, pois ele é imposto, como veremos, pelas exigências do próprio sistema. Entretanto ele levanta questões que merecem ser abordadas, em primeiro lugar, por elas mesmas. Uma delas refere-se ao caráter único do espaço, a outra concerne à prioridade atribuída à intu.ção pura do espaço.

Que significa o fato de haver um só e mesmo espaço contendo em si todos os espaços particulares como partes? Em outras palavras, o que é que legi ima a pressuposição implícita da homogeneidade do espaço?

Com efeito, para que o espaço seja único é necessário que todos os fenômenos submetidos a determinações espaciais sejam ligados uns aos outros. Uma tal unidade do espaço implica pois em que os fenômenos espacialmente ligados, ou podendo sê-lo, sejam todos de mesma natureza e que, consequentemente os espaços particulares, constituidos por certos conjuntos de fenômenos sejam sempre homogêneos, como partes do mesmo espaço. Isto, se queremos conservar o caráter relacional do espaço e evitar confundir seu conceito com a noção vaga de um receptáculo universal.

Mas, se é assim, há que supor-se que um princípio de restrição tenha sido introduzido relativamente aos fenômenos considerados.

Sem dúvida Kant o introduziu, pois o espaço do qual postula a unidade só pode ser o espaço físico e os fenômenos ligados num só e mesmo espaço, os corpos físicos. Mas esta restrição é feita sem maiores explicações, o que não está isento de significação filosófica .

Não podemos sempre supor conjuntos heterogêneos de fênomenos, que não podem pois ser reunidos num mesmo sistema espacial? Não existem, para o próprio Kant, fênomenos empíricos e "fênômenos" que não o são, como as figuras da Geometria? Como ligar, por exemplo, um triângulo a um metrônomo num só e mesmo espaço, se o triângulo só tem uma existência, por assim dizer, "imaginária" (ideal) e o metrônomo é um corpo físico? Antecipamos já, por este exemplo, o problema da aplicação da Geome ria 
ao mundo físico. Mas seja qual for esta ap'icação, ela não autoriza a situarmos corpo físico e figura geométrica num só e mesmo espaço.

Ora, não é certamente o que faria Kant, que não poderia cometer semelhante contrasenso. E preciso pois procurar também a partir das relações entre o espaço físico e o espaço geomé rico a razão de sua tese relativa à unidade do espaço.

Permanece o fato de que esta tese requer que o espaço que se considera único seja o espaço físico, o espaço que ordena a classe de corpos físicos. Nada impede entretanto que concebamos outros espaços além do físico e que lhe seriam heterogêneos. Por exemplo, os espaços sociais, que uma concepção relacional do espaço não poderia excluir. Mas então como admitir a doutrina kantiana que faz do espaço, como intuição pura, um espaço único, sem reconhecer que ela torna impossível pensar uma pluralidade de espaços não homogêneos ao espaço físico e, enquanto não homogêneos, não podendo ser partes dele?

Quanto a esta impossibilidade, em Kant, de pensar outros espaços além do espaço físico (e o espaço euclidiano que é a sua idealização), não seria ela correlativa ao fato do espaço pertencer, exc'usivamente, à esfera da sensibilidade?

Uma tal limitação é a mesma que limita o conceito kantiano de experiência apenas como experiência do mundo físico.

Considerando a reserva imposta por esta restrição, vejamos agora um outro aspecto da tese do espaço único como intuição pura, relativo, desta vez, à prioridade de sua intuição.

A representação de um espaço único é anterior à representação de espaços particulares. Em ou ros termos, a representação de diferentes espaços pressupõe a de um espaço único, não sòmente pensado, mas dado numa intuição a priori.

Mas não podẹmos perguntar se a pressuposição inversa não é também igualmente válida? Pois mesmo se toda representação de espaços particulares implica a representação de um espaço único, do qual os espaços particulares seriam partes, como recusar a implicação recíproca, isto é, que a representação de um espaço único não pressupõe igualmente a representação de espaços particulares?

A implicação recíproca não pareceria estar mais de acordo com a concepção do espaço como forma dos fenômenos exteriores? Mas uma resposta afirmativa a esta questão, embora legítima em si mesma, ignoraria as exigências que comandam a elaboração da Es ética Transcendental. 
Kant está persuadido, e veremos adiante por quais razões, que as proposições da Geometria, que são determinações de propriedades do espaço, são construidas na intuição sensível pura. Mas para que uma tal construção seja possível é preciso, segundo e'e, que seja dada uma intuição pura do espaço anterior a toda intuição empírica dos fenômenos exteriores, isto é, uma intuição a priori.

Ora, como é nela que podem ser construidas as figuras e as propriedades que determinam geometricamente o espaço, esta intuição pura deve igualmente corresponder, em suas propriedades essenciais, àquelas que caracterizam o espaço da geometria, o qual aparece, assim, como a imediata objetivação dessa intuição. Estas propriedades essenciais, que são a unidade e a infinidade, não se deduzem entretanto da intuição pura. É, pelo contrário, o fato de serem dadas a priori como implicadas em toda representação de um espaço que prova, para Kant, o caráter de intuição a priori atribuido ao espaço.

Assim, da mesma forma que o espaço é primeiramente representado como único, é representado também como uma grandeza infinita dada. Ora, a infinidade exclui por sua vez que ele seja um conceito geral, pois não há conceito geral que possa determinar, por si mesmo, alguma coisa em relação à grandeza. O espaço é, pois, confirmado como intuição. E uma intuição pura, já que nada de empírico pode ser dado como infinito - a infinidade sendo aquilo que supõe "um infinito sem limites no progresso da intuição, um "eu posso sempre pensar um espaço maior e assim por diante".

Enfim, como grandeza infinita, o espaço é o que torna possível a representação de quantidades particulares de extensão, os quania, como sendo a totalidade que os precede e da qual eles são apenas as partes. Aqui poderíamos colocar a mesma ordem de questões que foi suscitada pe a tese da unicidade apriorística do espaço, uma vez que é o mesmo argumento que sustenta a atribuição tanto da unicidade quanto da infinidade à intuição pura do espaço. E ainda uma vez a argumentação de Kant deve ser colocada na perspectiva da solução que ele pretende dar ao problema da possibilidade da Geometria .

Lembremos também que a doutrina da intuição pura, que deve dar conta da possibilidade da Geometria, responde a uma outra exigência não menos essencial na obra de Kant, e que já entrevimos, a saber, a legitimação da aplicação da Geometria aos fenômenos físicos.

É um único e mesmo espaço que é in uição pura e forma dos fenômenos exteriores e isto permite compreender que as verdades 
geométricas "constru:das" no espaço como intuição pura possam valer para a determinação espacial de fenômenos exteriores dos quais este mesmo espaço é a forma. A partir daí as figuras geométricas e suas re'ações poderiam aparecer como esquemas imanentes à percepção dos fenômenos exteriores .

A aplicação da geometria aos fenômenos do mundo físico es'á assim legitimada. Ainda mais, a verdade desta aplicação repousa no fato de que postulamos uma raiz única do espaço físico e do espaço geométrico, e que postulamos que esta raiz seja o espaço como condição subjetiva da sensibilidade, o que funda, assim, uma tal aplicação na estrutura a priori do próprio sujeito.

Desta dou rina do espaço como intuição a priori poderíamos consequentemente destacar as seguintes implicações:

19 A Geometria euclidiana é a única geometria possível, pois o espaço euc.idiano recobre perfeitamente a intuição pura do espaço no Sujeito.

2. ${ }^{\circ}$ Como existe identidade entre o espaço como forma dos fenômenos físicos e o espaço como intuição pura, que recobre c espaço euclidiano pressuposto pelas verdades da Geometria, estas verdades devem necessàriamente poder aplicar-se a todos os fenômenos físicos sob o ponto de vista de suas determinações espaciais. Em resumo, a estrutura do espaço físico é necessàriamente euclidiana.

Ora, uma consideração recorrente da solução kantiana, seja em relação ao problema da Geometria, seja em relação ao probleblema de sua aplicação aos fenômenos físicos, reve'a-a como ní idamente insatisfatória, e até mesmo falsa, se se leva em conta, por exemplo, as implicações que acabamos de enumerar. Todavia, a concepção kantiana está longe de ser aberrante se permanecemos ùnicamente na perspectiva da Geometria de Euclides. Algumas considerações rápidas sobre o quê, na Geometria euclidiana, tornava possível a maneira como Kant a encarava nos permi irá ver melhor a quê a tese do espaço como intuição a priori tentava responder. Correlativamente, poderemos constatar como não decorria desta concepção a necessidade de uma conexão essencial entre a ciência (em particular aqui sob seu aspecto demonstrativo) e a esfera dos signos, que não receberá, aliás, estatuto pró prio na filosofia de Kant.

Já acentuamos que a tese da intuição a priori visava conciliar o duplo fato inerente, segundo Kant, às proposições geométricas: seu cará er sintético (não analítico) e seu caráter necessário (não 
empírico ) (5). Segundo uma tal concepção há pois um nítido privilégio concedido à intuição em detrimento da demonstração na constituição da obra de Euclides. Como se justifica isto?

Parece que Kant atentou bastane para o apelo que se faz, frequentemente de forma implícita, à intuição, no decurso das demonstrações de teoremas nos Elementos de Euclides. Mas em vez de considerar tal apelo como significando falhas no aparato demonstrativo euclidiano, ele o toma como prova do caráter eminentemente intuitivo das verdades, geométricas. Donde a tese da construção dessas verdades na intuição pura do espaço (6).

Assim, Kant não se engana ao constatar a importância da intuição na Geometria de Euclides. Como diz R. Blanché, "se as demonstrações geométricas clássicas são tomadas como modelos, então é verdade que a intuição - contemplação e mesmo construção - nelas deve interferir" (7). Da mesma forma, para Strawson, a concepção kantiana da "construção na intuição pura" permanece uma descrição aceitável do recurso efetivo à intuição subjacente à Geometria de Euclides (8). Mas Kant começa a enganar-se quando crê poder fazer da figuração, da construção na intuição sensível pura, o essencial da Geometria; em outras palavras, quando toma o estado de fato da Geometria de Euclides por uma necessidade de direito. Pois ele se fecha ao movimento que seguirá a Geometria, isto é, o aperfeiçoamento do aparato demonstrativo, afim de assegurar o caráter lógico da construção. Movimento que esclarece, outrossim, o que já era essencial em Euclides: a demonstração, apesar das omissões que os reiterados apelos à intuição suplementam, e que aparecem mais como avatares da Geometria em sua origem.

Com efeito, enquan o para Kant o valor de necessidade das proposições geométricas repousa na evidência intuitiva a priori da construção das figuras e de suas relações espaciais, os geômetras a buscarão do lado de seu encadeamento dedutivo. A necessidade de

(5) Ver, por exemplo, nos "Prolegôménes...", trad. francesa Gibelin, 1963 pg. 48-49, a próposito da não coincidência dos simétricos - que serve, entre outros argumentos, para fundar o caráter sintético da Geometria .

(6) Cf. Critique de la Raison Pure, trad. citada, pg. 493. Estas consideraçôes ultrapassam por vezes o quadro da Estética, mas cremo-nos autorizados a fazê-las, pois é precisamente na Estética que se encon'ram, na doutrina do espaço e do tempo como intuições sensíveis, as premissas da concepção kantiana da Matemática.

(7) Cf. R. Blanché, L'Axiomatique”, PUF, 1955, cap. I, pg. 8.

(8) Ver P.F. Strawson, "The Bounds of Sense, An Essay on Kant's Critique of Pure Reason", 1966 (pg 283). 
tipo lógico é, pois, a única pertinente para o geômetra. Assim, mesmo admitindo a intuitividade dos axiomas originais na Geometria de Euclides), não se recorre à intuição para aí assentar a demonstração de teoremas, os quais devem ser inteiramente deduzidos.

Enfim, o engano vai se confirmar quando, não concebendo algo como um trabalho de idealização, como o fará Husserl na Origem da Geometria, Kant põe as proposições geométricas e o espaço euclidianos como conaturais à nosso espírito. Assim, a concepção de uma contrução de proposições geométricas na intuição a priori não se contenta com ser simplesmente descritiva, mas pretende ser determinante das condições de possibilidade de toda geometria. Dessa forma ele limita o pensamento do espaço, já que este não pode possuir outras caracterís icas além daquelas do espaço euclidiano, que se torna assim uma espécie de espaço absoluto. E como este espaço não é, em verdade, mais do que uma certa idealização do espaço físico da experiência cotidiana, compreende-se as implicações que acentuamos acima relativamente ao espaço geométrico e as relações entre o espaço geométrico e o espaço físico.

Além disto, a interpretação figurativa da Geometria, contrapartida da função secundária assinalada à demonstração, concorda com a ausência de interrogação acerca da necessidade do recurso à escritura simbólica para a constituição da Matemática. Unicannente desejoso de mostrar o caráter não essencial do traçado físico das figuras, Kant negligencia a consideração do caráter intrinsecamente simbólico da Matemática, aí incluida a Geometria, se se toma a sério as exigências colocadas por uma demonstração rigorosa bem como o destaque das estruturas matemáticas gerais que se encontram presentes na própria Geometria. A partir daí, ele pode não levar em conta a empresa cartešana de algebrização da Geometria .

Certamente, poder-se-á objetar que Kant não ignora a utilização de "representações simbólicas" em Álgebra, mas este recurso não é tematizado por ele. Com efeito, os símbolos algébricos, são tomados por Kant não em função das operações algébricas às quais reenviariam as manipulações de que são objeto, mas sim em função das significações que são susceptíveis de receber unicamente pela substituição numérica, sendo o número concebido como uma simples grandeza (quantitas) construida na intuição sensível (do tempo). (9).

Podemos, pois, dizer que, para Kant, a imagem pura, a in'uição sensível, absorve o símbolo.

(9) Vuillemin, obra cit., pg. 49. 
E verdade que esta ausência de consideração da escritura simbólica, como intrínseca às matemáticas, se inscreve no horizonte mais vasto da não tematização da linguagem no interior da concepção kantiana do conhecimento.

Tendo em vista que só nos in eressamos pela epistemologia kantiana através do eixo de nossa problemática do espaço, vejamos o que, já na exposição deste conceito, fazia prever uma tal omissão.

Acabamos de ver como, no que concerne às Matemáticas, esta ausência de uma tematização da linguagem, sobretudo na sua forma simbólica, derivava da doutrina da construção de "verdades" geométricas na intuição sensível pura do espaço. Resta-nos pois fazer ver o que anunciava também esta omissão na exposição do espaço como forma dos fenômenos exteriores.

Enquanto forma dos fenômenos, o espaço é o que permite a ordenação da diversidade fenomenal segundo certas relações, a saber, a exterioridade em relação a nós, a justaposição dos fenômenos uns em relação aos outros, sua distinção quanto aos lugares (10). Mas esta ordenação segundo certas relações só é pensada em função da intuição sensível, isto é, de um ver. Além disso, a exterioridade, a justaposição dos fenômenos, consequentemente a diferenciação dos lugares, são as de objetos num quadro, a da representação. Relativas às condições subjetivas desta representação, as propriedades espaciais dos fenômenos não são ao mesmo tempo postas como correlativas de uma orientação e de um arranjo efetivos. Devido a isto restringimos a experiência do espaço, ignorando-o como pressuposto igua'mente por nossas operações e ações no mundo. Certamente Kant não ignorava que as ações e as operações do sujeito no mundo pressupõem o espaço, mas não reconhecia este fato como pertinente para sua investigação das condições da possibilidade da experiência, na perspectiva - por ele adotada - de uma determinação dos limites do conhecimento.

Entretan o, esta negligência iria limitar, desde a abertura da Estética Transcendental, o alcance de sua epistemologia e não iria permitir caracterizar a atividade do sujeito cognoscente da Crítica senão como não-laboriosa, segundo a expressão de G. Granger.

Que significa isto? Vejamos primeiramente o que ‘eria significado reconhecer o fato deste outro aspecto do espaço.

Compreender o espaço como pressuposto pelas nossas ações e operações no mundo é compreender que ele não é soòmente a "forma dos fenômenos exteriores" enquanto visados numa intuição, mas

(10) Cf. Critique de la Raison Pure, trad. cit., pg. 56. 
enquanto podem ser manipulados, deslocados, transportados, sransformados ou enquanto podem servir de horizonte para tais operações, ou pontos de partida, pontos de chegada ou caminhos de nossas ações. É por essas operações e ações, e não unicamente enquanto percebidas, que se desvelam as determinações espaciais: o ser fora, ao lado, entre, etc...

Notemos desde já que dessa negligência aliada ao fato de que só a Geometria euclidiana possa se aplicar, segundo Kant, aos fenômenos exteriores, segue-se, a partir da Crítica, uma dupla consequência. Primeiramente, certas relações espaciais de posição, intrínsecas à experiência ordinária do espaço como forma dos fenômenos exteriores - por exemplo, a relação "entre" - que não interessam à Geometria de Euclides, permanecem não tematizadas e não se é capaz de assinalar a possibilidade de um tratamento matemático que possa exprimi-las. Da mesma forma não é indicado, ou ao menos tornado possível, nenhum lugar epistemológico que permitisse considerar a possibilidade de tratar matemáticamente como o fará, por exemplo, a teoria dos gráficos - as relações espaciais implicadas por certas operações e ações no mundo.

Ora, por outro lado, tais operações e ações não concernem apenas às nossas relações pragmáticas com os fenômenos, mas interessam também aos processos de conhecimento, mesmo dando aqui à palavra conhecimento o sentido forte de conhecimento científico. Não sabemos que uma manipulação técnica - para nos mantermos na generalidade de um exemplo, o que é suficiente para nosso objetivo - é necessária para isolar dos fenômenos empíricos os objetos cientificamente pertinentes, e que, consequentemente a atividade científica transforma efetivamente, em vez de somente receber seus fenômenos numa simples intuição sensível? Não é neste sentido que a química chega a seus elementos após um longo trabalho de depuração dos dados naturais?

Es'a é a razão porque podemos dizer que uma concepção do espaço como condição da experiência que reduziria sua consideração unicamente ao ponto de vista da intuição, impedindo assim seu desvelamento como mediação de operações e de ações, restringiria da mesma forma, desde o princípio, a concepção de experiência, e convidaria desde logo a não notar a parte de atividade laboriosa que a experiência requer. (Não pretendemos, bem entendido, reduzir a atividade laboriosa do cientista unicamen e às manipulações técnicas, que são aqui apenas uma ilustração bem particular do que pode ser exigido pelo pensamento científico).

Mas qual o liame que ligará a concepção de tais operações com a da linguagem? 
Se as consideramos na perspectiva do conhecimento científico, como no exemplo da Química que acabamos de citar, es'as operações não seriam independentes de uma certa linguagem. E para "realisar" fórmulas simbólicas ou para permitir constitui-las que muitas manipulações técnicas, por exemplo, são levadas a efeito. Estas fórmulas que integram o discurso científico são também as fórmulas por via das quais os objetos são visados e suas relações esclarecidas. O conhecimento científico não seria portanto uma simples determinação conceitual imediata da intuição sensível, mas uma determinação conceitual de objetos constituidos através das formas de uma linguagem.

Quanto às operações e manipulações da vida cotidiana elas também se encontram ligadas à linguagem (aqui a linguagem dita "corren'e"). Mas aproximar a linguagem das operações e das ações do "mundo-da-vida" não poderia significar que se considera a linguagem numa perspectiva pragmatista, o que seria tematizá-la apenas para encerrá-la imediatamente numa função instrumental, à qual não se poderia nunca reduzi-la?

Deixemos todavia para o momento em que abordamos $O \mathrm{Ser}$ e o Tempo de Heidegger a análise das relações entre o signo e a estrutura de recorno, a qual caracteriza os fenômenos enquanto são-para .... isto é, enquanto se mostram como disponíveis. Para antecipar digamos que as operações e as ações da vida cotidiana, que nos fazem desvelar os fenômenos sob o ângulo de sua disponibilidade, ela própria espacializante, não estão menos inseridos num horizonte de significações e de valores simbólicos. Destarte, as determinações espaciais dos fenômenos, que se dão, antes de qualquer perspectiva científica, tanto na percepção quanto através dessas operações e ações no mundo, estão elas próprias ligadas à esfera de significações e de investiduras simbólicas (11). Enfim, deter-se na consideração desta ligação abre a possibilidade de interrogar o espaço no terreno das ciências ditas humanas.

Assim fazemos entrever as questões que nos vão ocupar na parte positiva de nosso trabalho.

Mas agora, depois de ter indicado certos limi^es da tematização kantiana do espaço reduzido a ser apenas a forma dos fenômenos exteriores dados na intuição sensível e sendo ele próprio uma intuição sensível pura, é necessário voltar às relações entre o espaço

(11) Ver, por exemplo, o capítulo sobre o espaço de E. Cassirer, "The Philosophy of Symbolic Forms", vol. III e a questão que aí se acha colocada: Is the in which things are represented to us a simple intuitive datum, or does it follow from a process of symbolic formation"? (p. 143). 
e o tempo na Estética Transcendental para ver se tal análise pode nos esclarecer acerca do fechamento do horizon e problemático no qual o espaço foi considerado.

\section{Relações entre to espaço e o tempo na Estética Transcendental.}

Certamente a Estética Transcendental nos coloca no caminho da afirmação, que será explicitada depois pela Refutação do Idealismo, de que a intuição dos objetos no espaço é implicada pela intuição que o sujeito tem de si mesmo e de seus estados de consciência. Em outras palavras, toda representação é dada com seu representado do qual ela é inseparável, isto é, com o objeto visado nela e o espaço sem o qual não poderia ser intuído.

Veremos então que a realidade empírica do espaço assim posta (12) não pode ser reduzida em proveito de uma intuição da existência de si próprio e de seus estados internos que, como pretenderia um idealismo psico'ógico, seria independente da intuição dos objetos do sentido externo. Haveria assim, à primeira vista, uma certa equivalência das posiçóes respectivas do espaço e do tempo enquanto ambos são sempre requeridos por toda experiência possível. E se fosse necessário ver aí algum desequilíbrio, seria a favor do espaço e não do tempo, uma vez que o que está em questão é o problema do conhecimento, entendido sobretudo como conhecimento dos objetos físicos. Podemos ainda constatar que os conhecimentos sintéticos a priori de que se ocupa a Es ética Transcendental são antes de tudo os da Geometria euclidiana, que se relacionam principalmente ao espaço.

Entretanto, apesar deste fato, é necessário não perder de vista a orientação subjetiva que Kant pretende dar ao problema do co* nhecimento. Se os exempios sintéticos a priori são relativos principalmente a determinações espaciais como na Geometria ou a determinações espacio-temporais como no problema físico da mudança, não é menos verdade que a investigação acerca de nosso poder de conhecer leva a pesquisa para o lado das fontes mais subjetivas dos atos constitutivos do objeto de conhecimento e que é neste nível que é preciso abordar a questão das relações entre o espaço e o tempo.

Além disto, como o espaço e o tempo são apenas condições subjetivas da sensibilidade, e não das coisas ou das relações em si, é preciso que os tomemos enquanto tais, isto é, sob o ângulo desta idealidade transcenden al, para examinar suas relações.

(12) Cf. Critique de la Raison Pure, trad. citada, pg. 59 em "Consequências que seguem a exposição transcendental do conceito de espaço". Cf. também "Refutação do Idealismo" - teorema, pgs. 205, 206. 
Enquanto condição subjetiva da sensibilidade, sabemos que o espaço é a forma do sentido externo através do qual os fenômenos exteriores nos são dados. Paralelamente o tempo será mostrado como a forma "do sentido interno, isto é, da intuição de nós mesmos e de nosso estado interior" (13). Poderiamos então acreditar que o espaço e o tempo correspondem a duas regiões distintas da intuição: respectivamente a intuição dos fenômenos exteriores e a intuição dos fenômenos interiores, isto é, de nossos estados de consciência. Mas isto seria ignorar que, enquanto tais, todas as nossas representações estão em nós, e que elas devem pois se encadear segundo a forma do sentido interno. O tempo é, consequentemente, a condição subjetiva "sob a qual podem estar em nós todas as intuições". Segue-se daí que ele é a "condição formal de todos os fenômenos em gera", ao contrário do espaço, que "está limitado, como condição a priori, simplesmente aos fenômenos externos" (14).

Assim, quando se diz que "o tempo não pode ser uma determinação dos fenômenos exteriores", é para que se compreenda melhor que ele não está primeiramente dado do lado dos representados, como estaria o tempo físico, mas do lado subje ivo das próprias representações das quais ele determina imediatamente as relações.

Mas desde que as representações implicam seus representados e, consequentemente, os fenômenos exteriores, se se trata de representações do sentido externo, o tempo é também, embora mediatamente, a forma destes últimos, porquanto é a forma de todas as representações da sensibilidade.

Esta universalidade da intuição pura do tempo indicaria já um certo privi égio do tempo sobre o espaço como condição subjetiva da sensibilidade.

Como conciliar entre anto este privilégio com o fato de o tempo ser concebido segundo o modelo da linha? A escolha de um tal mod`lo não justificaria uma inversão das relações entre o tempo e o espaço, como teria visto Bergson (15)?

Que quer dizer, com efeito, Kant, quando afirma que "representamos a sequência do tempo por uma linha que se prolonga ao infinito e cujas diversas partes constituem uma série que tem ape. nas uma dimensão"?

A linha já não pressupõe o espaço e, em termos euclidianos, sua tridimensionalidade? Kant não o teria negado, mas isto não

(13) Critique de la Raison Pure, trad. citada, pg. 63, §b.

(14) Cf. Critique de la Raison, §F, trad. citada, pg 6. \$C.

(15) H. Bergson, "Essai sur les données immédiates de la conscience", PUF, Ed. do Centenário, pg. 69. 
implica em que ele subordine o tempo ao espaço. Pois o que é dito é que a intuição pura do tempo só é representável por analogia. Assim, é por suplementação que nos representamos a sequência do tempo por meio de uma linha prolongada ao infinito.

Mas deixemos para logo mais a interrogação acerca do que significa uma tal suplementação, isto é, o caráter de analogia atribuido à linha, para tomá-la primeiramente nela mesma, em sua qualidade de analogon. O que Kant pretende com a escolha de uma tal representação é precisamente fazer compreender a continuidade do tempo, enquanto, para Bergson, pelo contrário ele apenas lograva, com isto, a descontinuidade.

A linha é pois vista aqui por Kant não, com se poderia crer, na descontinuidade da justaposição de seus pontos, mas muito mais na continuidade de seu engendramento que pressupõe aliás, como condição subjetiva, o espaço tanto quanto o tempo.

Agora, quanto ao fato da necessidade do recurso analógico, ele pode revelar a'go sobre a maneira como nos encaminhamos para as fontes (ou a fonte) da constituição da transcendência. Com efeito, ele serve para indicar que se o tempo só é representável por analogia, ele deve ser, como condição subjetiva da intuição, uma fonte mais profunda que o espaço.

Quanto às relações entre o espaço e o tempo, a Estética Transcendental nos deixa pois esta indicação: o tempo, como condição subjetiva é ao mesmo tempo uma fonte mais profunda da representação do que o espaço, e é a condição universal, enquanto o espaço está limitado à representação do sentido externo.

Para pensar o que se vai derivar desta indicação relativa às relações entre o tempo e o espaço na Crítica, é preciso investigar como estas relações se articulam para além da Estética, ou seja, na Analítica e na Dialética Transcendentais .

Então, talvez, o que nos pareceu limitar o pensamen o kantiano acerca do espaço na Estética se esclarecerá melhor. 